\title{
An Investigation of the Socio-Economic Benefits of Small-Scale Gold Mining in Malawi
}

\author{
Tiyamike Haundi ${ }^{1, *} \mathbb{C}$, Gift Tsokonombwe ${ }^{1}$, Steven Ghambi ${ }^{1}{ }^{1}$, Theresa Mkandawire ${ }^{2}$ and Ansley Kasambara ${ }^{3}$ \\ 1 Department of Mining Engineering, The Polytechnic University of Malawi, Blantyre 312225, Malawi; \\ gtsokonombwe@poly.ac.mw (G.T.); sghambi@poly.ac.mw (S.G.) \\ 2 Department of Civil Engineering, The Polytechnic University of Malawi, Blantyre 312225, Malawi; \\ tmkandawire@poly.ac.mw \\ 3 Department of Mathematics and Statistics, The Polytechnic University of Malawi, Blantyre 312225, Malawi; \\ akasambara@poly.ac.mw \\ * Correspondence: thaundi@poly.ac.mw
}

Citation: Haundi, T.; Tsokonombwe,

G.; Ghambi, S.; Mkandawire, T.;

Kasambara, A. An Investigation of the Socio-Economic Benefits of Small-Scale Gold Mining in Malawi. Mining 2021, 1, 19-34. https:// doi.org/10.3390/mining1010003

Academic Editor: Jörg Benndorf

Received: 31 December 2020

Accepted: 15 February 2021

Published: 1 March 2021

Publisher's Note: MDPI stays neutral with regard to jurisdictional claims in published maps and institutional affiliations.

Copyright: () 2021 by the authors. Licensee MDPI, Basel, Switzerland. This article is an open access article distributed under the terms and conditions of the Creative Commons Attribution (CC BY) license (https:// creativecommons.org/licenses/by/ $4.0 /)$.

\begin{abstract}
In the recent years, there has been a surge in artisanal and small-scale gold mining (ASGM) in various districts of Malawi. Reports of a gold rush have emerged in various districts, including Mangochi, Lilongwe, Balaka, and lately in Kasungu. There has been persistence by many indigenous communities participating in ASGM activities, yet little is being done by the government to formalize and support the sub-sector. The purpose of this study was to investigate the benefits of artisanal small-scale gold mining in Malawi and expose the shortfalls so that key stakeholders and policy makers are well informed. A quantitative approach which used semi-structured questionnaires was used and the data was analyzed using Microsoft excel and Statistical Packages for the Social Sciences (SPSS). The study shows that ASGM is characterized by people with low literacy levels, who use traditional tools (low-tech) and use methods fueled by lack of capital, and deficiency of basic knowledge of mining and geology. The study found that the government could achieve substantial socio-economic development from the sector by: (1) revising the current artisanal and small-scale mining (ASM) legislation so that it embraces the customary practices whilst safeguarding the environment and improving the tax collection base; (2) providing support in form of mining related training and education to these communities; (3) leading in transfer of modern technologies for improved extraction; (4) supporting ASM cooperatives in securing credit facilities from financial institutions; and (5) closing the existing knowledge gap for ASM related issues through introduction of mining desk officers in district councils.
\end{abstract}

Keywords: artisanal small-scale gold mining; socio-economic impact; mining legislation; poverty alleviation

\section{Introduction \\ 1.1. Overview of Artisanal and Small-Scale Mining in Africa}

For decades, mining has been regarded as one of the most significant economic activities in Africa. The continent has made significant contributions towards manufacturing by supplying high value minerals to the rest of the world. At the moment, there are many large mining companies operating in various African countries, predominantly operating on a large scale basis. The continent's mining activities are also dominated by medium and small scale mining operations. Artisanal and small-scale mining (ASM) plays a more a prominent socioeconomic role in the rural, remote areas where there are minimal options for revenue generating activities [1]. ASM has offered employment to over one million people in the whole Southern African Development Community (SADC) region, as shown in Table 1, [2]. The areas in which ASM take place are characterized by unemployment and high illiteracy levels. The miners have little or no concerns over environmental degradation emanating from small-scale mining [3]. For example, in Zimbabwe, it is reported that 
small-scale miners are not compliant to mining safety and environmental regulations due to technical, financial, and socioeconomic challenges [4].

Table 1. Small-scale mining employment for selected African countries.

\begin{tabular}{ccc}
\hline Country & Estimated Number of Mines & Estimated Employment \\
\hline Angola & NA & 30,000 \\
\hline Burkina Faso & $35-60$ & 60,000 \\
\hline Chad & 2000 & $6000-12,000$ \\
\hline Ghana & $400-700$ & 30,000 \\
\hline Guinea & N/A & 60,000 \\
\hline Kenya & $50+$ & $4500+$ \\
\hline Madagascar & 83 & $5000-20,000$ \\
\hline Malawi & N/A & 40,000 \\
\hline Mali & N/A & 100,000 \\
\hline Mozambique & N/A & 60,000 \\
\hline Sierra Leone & N/A & 100,000 \\
\hline South Africa & NA & 10,000 \\
\hline Tanzania & 4000 & 100,000 \\
\hline Zaire & NA & 500,000 \\
\hline Zambia & 200 & 30,000 \\
\hline Zimbabwe & $2000-5000$ & 30,000
\end{tabular}

Source: International Labour Organisation (1999); Mining, Minerals and Sustainable Development Project (2002); and United Nations (1996).

Many studies have not quantitatively brought into perspective the socioeconomic benefits associated with ASM in Africa. It is important to capture the primary data to genuinely assess the socioeconomic benefits of the artisanal and small-scale gold mining (ASGM) activities. The primary focus of this study was to assess the socioeconomic benefits of ASGM activities. To achieve this, small-scale miners, as well as members of the communities in Malawi, were engaged to quantify the benefits emanating from the ASGM activities in the rural communities.

The global surge in ASM has engrossed millions of people looking for economic refuge in a world where $40 \%$ of all people live in poverty [5]. Various researchers define ASM differently due to the varying conditions which the sector is subjected to. However, most definitions are based on the form of labor, level of machinery involved, and legality of the activity. For example, Zvarivadza [6], defines ASM as a form of mining which involves exploitation of marginal ore deposits, using elementary tools such as picks, shovels, wheelbarrows, panning dishes, and so on, which are profitable when mining on a large scale. In many cases of ASGM activities in some parts of Africa, miners work as individuals, and or in groups. In most cases, members of the same family belong to the same group. Miners either mine for direct sale to the customers or the purchasers hire the miners with a pre-agreed amount to search for the alluvial gold and sell them when the precious mineral is found. The advantage of the former is that the miner has the liberty to identify another customer with a better offer when the deposit is extracted and processed.

\subsection{Mining in Malawi}

Malawi is endowed with deposits including: uranium, bauxite, coal, gold, niobium, nickel, and precious stones, and is estimated to have significant deposits of graphite and rare earth minerals. Despite this, the contribution of Malawi's mining sector to the gross domestic product (GDP) was less than $1 \%$ in the 2016/17 financial year [7]. In 
2010, Malawi's first significant, and relatively major, mining operation for uranium at Kayelekera in Karonga district, situated in the northern part of the country, spurred the contribution of the sector to GDP from less than 3\% in 2005 to $10.8 \%$ in 2010, indicating the potential of the sector to the country's economy [8]. For many years, production has been dominated by bituminous coal, gemstones, limestone, and quarry stone. Mostly, gemstones are primarily mined for export, and sadly, a portion of them are not reported due to smuggling [9]. Recently, there has been an increase in artisanal and small scale gold mining activities in various districts of the country. The government was unable to stop the illegal artisanal gold mining in various districts, such as Mangochi, Balaka, and Lilongwe, despite several attempts to curb the practice. It is evident that ASGM is an important development prospect in Malawi and other developing countries. It has the capacity to contribute directly to poverty alleviation by creating economic activities to local communities whose levels of education are low. Most of these communities rely on farming as the major income-generating activity. Although unregulated small-scale mining is highly characterized by social and environmental problems, there is also an opportunity to transform mineral wealth into lasting solutions for local communities [10]. Malawi's mining sector is considered to be one of the forces toward achieving economic development. The sector has been stated as a thematic area in the national development agenda as stipulated in the Malawi Growth Development Strategy (MGDS) I, II, and III. In particular, MGDS III advances strategies towards participation and regulation of artisanal-, small-, and medium-scale miners [11]. There have been increasing numbers of ASGM activities in Malawi over the past few years. It is noted that ASGM activities are performed in remote areas, predominantly along riverbanks for alluvial gold deposits. It involves excavation of the alluvial soils in riverbanks and beds, as well as inland excavations. The excavated gold-bearing material is heaped in proximity to the water sources for washing, and subsequently the panning procedure follows.

Grynberg et al. [12] report that high cost of living, unemployment, and opportunities for employment are prominent factors triggering participation in ASGM, whereas gold price was found to be a significant pull factor. They concluded that the ASGM is a significant employer. Mwakumanya et al. [13] investigated, through a participatory action research process, the challenges facing women in ASM in Kenya, and developed strategies to counter the same through socioeconomic, legal, and environmental empowerment. Other publications, such as $[3,4,11,14]$, have emphasized the environmental aspects of ASGM, giving limited attention to the socioeconomic benefits of the subsector. It is evident that the aforementioned publications address the socioeconomic aspects of ASGM from an employment perspective, and environmental issues. This therefore necessitates capturing the primary data to objectively assess the socioeconomic benefits in terms of revenue generation, tax contribution, and contribution of ASGM to the standard of living in the rural areas of Malawi. Furthermore, there is limited research into the ASGM subsector in Malawi despite its potential to alleviate poverty in rural communities. This study builds on the little information which is currently available so that policy makers and other stakeholders are well informed on the socioeconomic benefits of the sector.

\subsection{Study Area and Gold Occurrences}

Gold occurrence has been reported in a number of localities across the country including Nathenje, Nkhotakota, and Mangochi-Makanjira areas [15]. Nathenje gold occurrence sites are located about $25 \mathrm{~km}$ ESE of Lilongwe City. From the city, the localities can be accessed through the M1 road. From Nanthenje Trading Centre, the sites can be reached by a gravel road that branches at Matapira Turnoff $1 \mathrm{~km}$ before Ntenthela Trading Centre northward passing through Kasina Trading Centre. The illegal mining activities in this vicinity is taking place at two locations; namely Mtalira Valley, located $2.1 \mathrm{~km}$ north-northwest of Matapila Trading Centre, and Mzeka Village, $2 \mathrm{~km}$ west of the same trading center.

Alluvial gold has been known to occur in Unga river basin in Makanjira, Mangochi area since 1937 [16]. The gold was found to occur in gravels of old river terraces. Illegal 
gold panning was first reported to the Department of Mines in May 2017. These mining activities are mainly taking place along three rivers; namely Unga, Lugola, and Litisa, and in Namizimu Forest Reserve.

In addition to the stated sites, a number of locations have been reported to host gold where illegal mining activities are said to take place. These locations include Kasungu and Chitipa districts. However, the current study focused on three localities; namely the Makanjira, Lisungwe, and Nathenje sites.

\subsection{Geology of Gold Concurrency Areas}

\subsubsection{Nathenje Area}

The geology of Mtalira Valley is briefly described in the Geology of the LilongweDowa Area (Bulletin number 26) by [17]. The geology of Mzeka Village falls within bulletin number 23 of the Geology of the South Lilongwe Plain and Dzalanyama Range by [18]. The general geology of the area falls within the basement complex gneiss and schists of predominant semi-pelitic. Psammitic, pelitic, and calcareous horizon occurs within these rocks which show quartz vein and migmatization. The area is dominated by superficial deposits obscures most of the basement, especially in the western side. Concordant and discordant amphibolite bands and minor basic and ultrabasic intrusions also arise.

Biotite gneiss is partially outcropped, including in the Matapila area. In addition to biotite gneiss, outcrops of schist that are argentiferous in part were exposed in the southwest part, whereas a small section of solvsbergite outcropped in the northeast. Patches of garnetiferous-hornblend pyroxene exposed from east to west. Gold is mainly mined in gravel alluvial in most of the valleys of the area.

\subsubsection{Kirk Range and Lisungwe Valley}

The geology of Kirk Range and Lisungwe is composed of a greater variety of schists and gneisses [19]. Additionally, many of the gneisses are quite extensively migmatized, with repeated horizons caused by isoclinal folding. Individual bands are thought to represent the original sedimentary formations in order of deposition.

Gold concurrency in Lisungwe Valley is known since 1900 [19], discovered in stream sediment gravels and sand at Mwandangombe Stream and Lisungwe (Figure 1). In Lisungwe drainage basin, gold occurred in a quartz vein. The main source of the gold appeared to be in the stringer types, usually concordant with the foliation of the paragneissic country rocks, and of the various Lisungwe tributaries known as Little Chisumbwiti and a southern branch of the Chitumbi. According to Chisambi [20], gold mineralization at Manondo-Choma within Lisungwe valley is hosted in biotite gneiss and schist associated with sulphide mineral paragenesis. Mineralization coincides with regional structures trending in a NE-SW strike direction. 


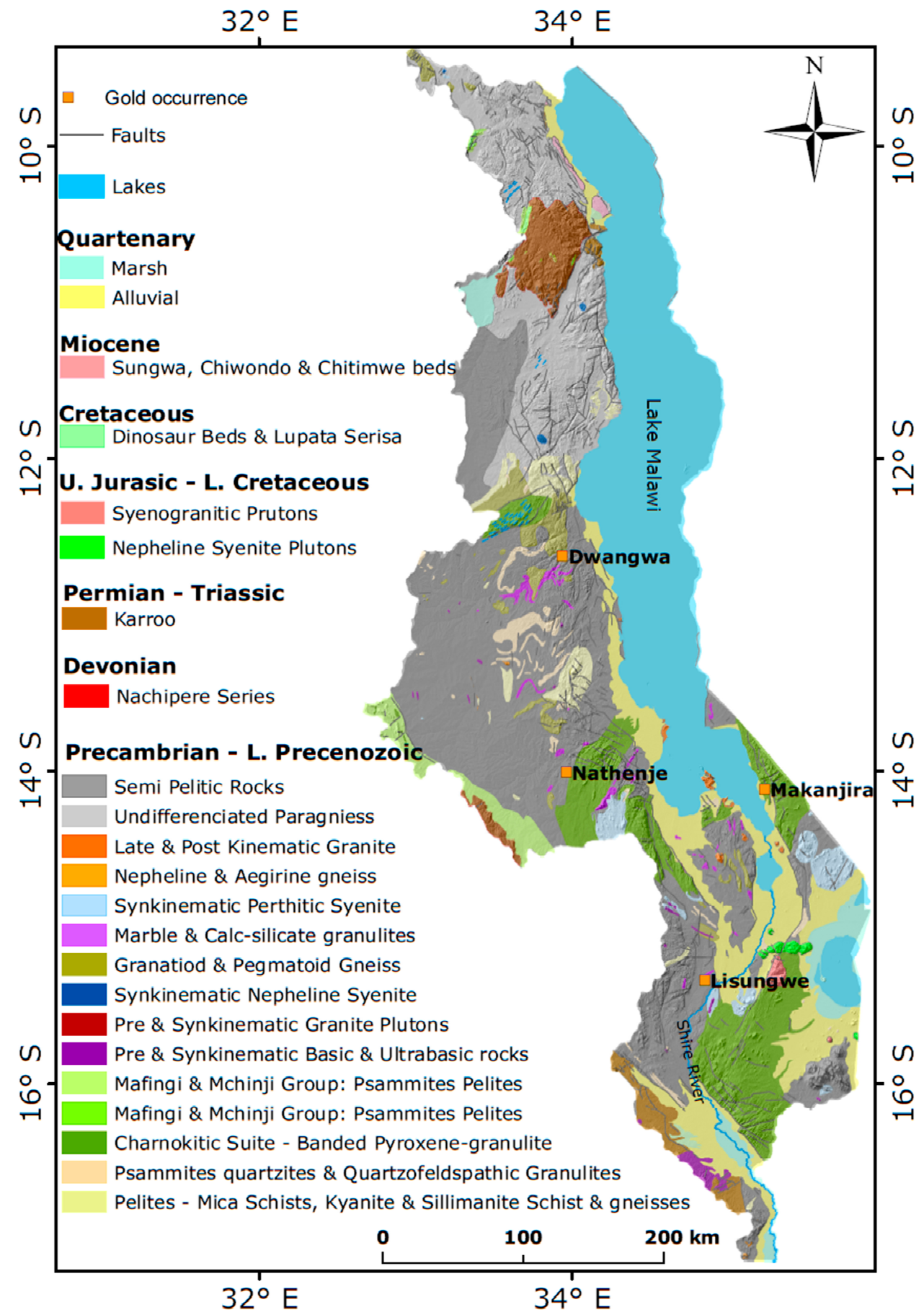

Figure 1. Some of the locations of gold occurrence in Malawi's geology (Source: modified from Geology and Mineral Resources of Malawi, 1973).

\subsubsection{Makanjira Area}

The geology of the Makanjira area is covered within Bulletin number 35 of the Geology of the Mangochi-Makanjila area [16]. The area is underlined by the same basement complex rock of Precambrian to Lower Paleozoic forming part of the Mozambican Orogeny with granulites predominated by charnockitic of sedimentary origin and associated with intrusions during the first structural metamorphic episode. Gneiss predominated by upper amphibolite facies mineral assemblages derived from pyroxene granulites during the second phase of metamorphism or paragneiss associated. Several granites and syenite bodies are associated with second structural metamorphism. 
Alluvial gold has been known to occur in the Unga river basin in the Makanjira, Mangochi area since 1937. The gold was found in gravels of old river terraces.

\subsection{Legislative Provisions}

Lack of clear information of whether a country allows ASM or not, and the underlying conditions regardless of land titles and mining licenses, speak volumes of how the sector is marginalized. Between 2017 and 2019, there were several cases of illegal ASGM in various places in Malawi. Several scholars, including the authors of [5], have recommended that the foundation of intervention activities in ASM communities should not just focus primarily on pollution abatement, capacity building, or technology transfer, but rather formalization of miners through rights recognition.

ASM has been legal in Ghana since 1989; however, less than 25\% of the miners operate legally [1]. In Democratic Republic of Congo, more than $90 \%$ of gold production and export is informal, indicating that the state has lost control [21]. In Malawi, the Mines and Minerals Act [22] provides for registration of ASM. Furthermore, it provides clear requirements for ASM investment, just like the medium and large-scale mining requirements, however, the problem is public sensitization and awareness of mining laws. Malawian legislation grants the permit to the holder to mine for minerals subject to the restrictions on the scale of operation and manner in which the minerals can be mined. However, the recent challenge in Malawi was on artisanal small-scale gold mining activities which were done outside the provisions of the law. The Mines and Minerals Act [22] restricts ASM or small-scale mining to Malawian nationals and does not provide a clear path for locals to partner with law-abiding foreigners who have the financial muscle to support mineral extraction [22].

\section{Materials and Methods}

\subsection{Study Sites}

The study was undertaken in three sites, namely Lisungwe valley, Makanjira, and Nathenje areas (Balaka, Mangochi, and Lilongwe districts respectively) which have records of illegal gold mining in Malawi (Figure 1). The reason for this was to develop a general overview of the socio-economic and environmental impacts of small-scale gold mining, as it is evident that in these sites there have been ASM gold rushes in the recent past.

\subsection{Study Design and Method}

The research employed a cross-sectional approach. Using this approach, data were collected from randomly selected participants at a single point in time. This approach offers the advantage of gathering data in a relatively short space of time. The rationale for using a cross-sectional survey was that the research topic is not investigating the trends of parameter(s) over time. The study used a quantitative approach because it mainly contained collection and analysis of quantitative data. The data was collected through the use of semi-structured questionnaires and site observations. This data was processed, analysed and interpreted with the aid of Microsoft Excel, as well as Statistical Packages for Social Sciences (SPSS). Statistical parameters which establish the significance of the findings were used to draw conclusions of the study.

\subsection{Study Populations and Its Characteristics}

Men and women of productive ages between 18 to 55 years were targeted. It also focused on individuals who were involved with the mining exercise regardless of whether they were in-migrants of the local communities or not. Furthermore, it involved individuals from neighboring communities who were not involved in the mining activities but were directly or indirectly benefiting from the activities. The involvement of participants who were not involved in mining was to ensure that balanced and credible information was obtained from both sets of people, i.e., those who were benefitting and those with minimal or negligible benefits. 


\subsection{Sampling and Recruitment of Participants}

A simple random sampling technique was used in identifying participants. In this technique, each individual in the population has an equal probability of part of the survey [23]. Therefore, bias in sampling of individuals was minimized so that the collected data was reliable and credible. With random sampling, a representative sample from a population provides the ability to generalize to a population. In this study, participants were selected systematically. A member was randomly picked from one household and the selection in the neighboring two households was skipped. A single participant was selected per household. This entails that the total population was based on the number of households involved and not necessarily the count of actual individuals in all the sites. This approach was considered on the basis that members from the same household were more likely to give similar responses. The study ensured that the sample population (number of households involved) was represented by the following characteristics:

1. Recruitment of participants regardless of gender, and a single participant was picked from a household;

2. Malawian citizens participating in the mining activities regardless of whether they were in-migrants of the area or not;

3. Individuals who lived near the sites where ASM activities were taking place;

4. Individuals who were actively participating in the ASGM activities either as workers, vendors or those selling food items and related materials around the mine sites

5. Age range of 18 to 55 years

6. Individuals with any level of income and education

7. Residents of the immediate surrounding villages who were not participating in the mining activities

Sample Size of Participants

The sample size was determined by considering the participants who were both directly and indirectly involved with the ASM activities. The following formula was adopted from [24] for determining overall sample sizes for the study:

$$
n=\frac{P(100-P) Z^{2}}{E^{2}}
$$

where:

$n$ is sample size

$p$ is the percentage occurrence of a state or condition

$E$ is the percentage maximum error required

$z$ is the value corresponding to level of confidence required

The level of precision or margin of error for this study was selected as $5 \%$ as it is acceptable for social research [23]. The level of confidence for this survey is $95 \%(0.05$ : representing a $\mathrm{z}$ value equal to 1.96). The variance or heterogeneity of the population ( $\mathrm{p}$ ) was $50 \%$, which is in agreement with [25] where it is recommended that researchers need to use $50 \%$ as the value of $p$ because this value result in the maximization of variance and produce the maximum sample size. Based on the above parameters, this study used an estimated sample size of 125 households in the study sites.

\section{Results and Discussions}

\subsection{Demographics}

The study was conducted in three districts, namely Lilongwe, Balaka, and Mangochi; with the total number of respondents being 125 . The majority of the respondents were from Lilongwe in Traditional Authority Mazengera (Figure 2a). Most of the respondents $85 \%$ were married and $21 \%$ of the respondents had at least secondary school education level (Figure $2 b, c)$. The average age of respondents was 38 years and average number of children in the households was 4 . 


\section{Study participants}

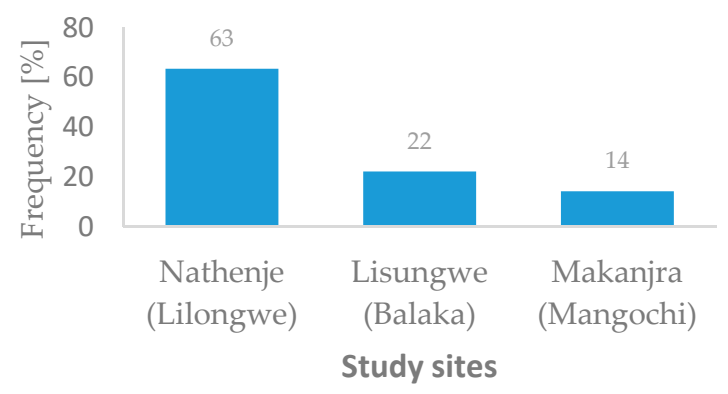

(a)

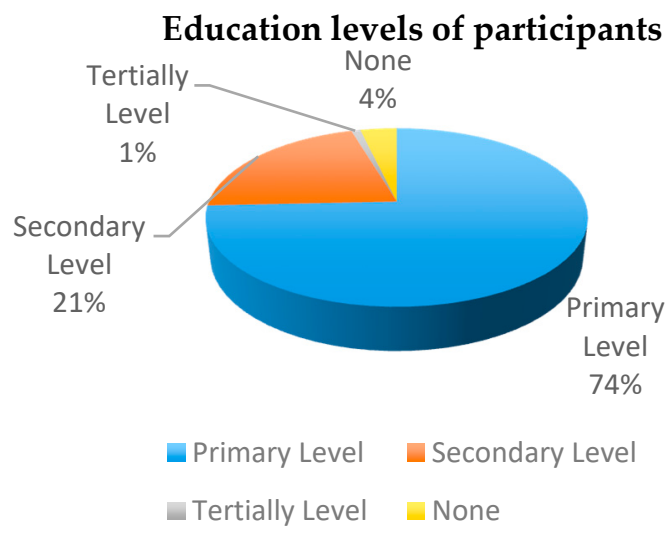

(c)

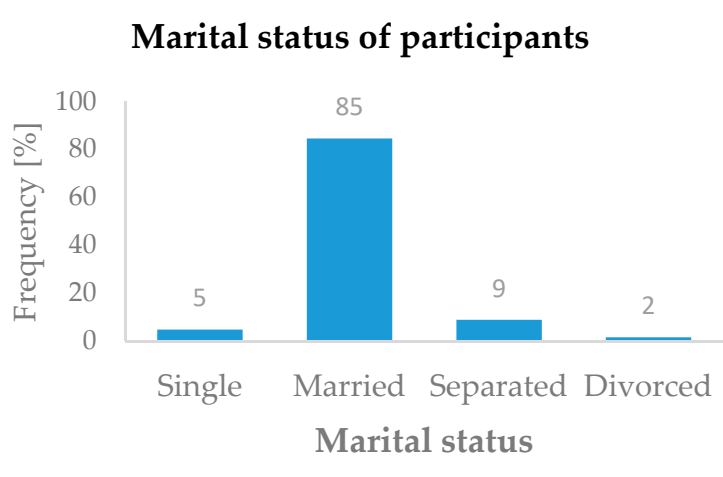

(b)

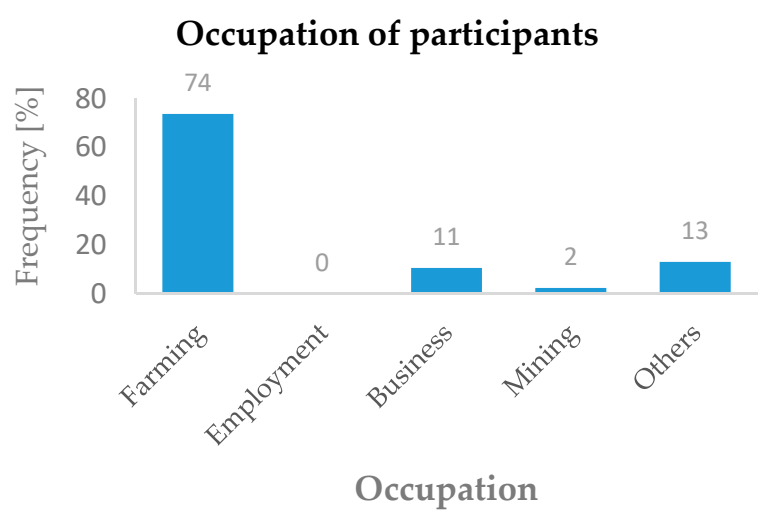

(d)

Figure 2. Summary of demographics. (a) Study sites and the distribution of participants on each site, (b) marital status of the participants and their distribution, (c) education levels of participants, and (d) occupation of participants.

Farming was the main occupation of the respondents (74\%), while others relied on piecework and small businesses; $2 \%$ of the respondents considered mining as an alternative occupation (Figure 2a). Furthermore, the respondents indicated that no one is formally employed in their communities, this makes sense as these sites are in remote areas where the majority of the people bank on farming as a major economic activity to support their livelihood. Figure $2 \mathrm{a}-\mathrm{d}$ shows the summary of demographics of participants in all the study sites.

\subsection{Summary of Site Observations}

Complex labor networks and systems are masterminded collaboratively by the miners, and buyers were observed on the visited ASGM sites. The following observations were noted.

Landowner/pit owner arrangement: the landowner finds resources and or materials for extraction and processing of the gold and hence directly benefits from the sales. Alternatively, the landowners rent out a portion of the land to miners for the extraction activities.

Collaborations: most miners prefer working as individuals (73\%), while some work as family companions, and few as friends (Figure 3a,b). The latter enables them to share the responsibility of financing activities and being directly involved in the manual work. Figure 3 presents a summary of these observations. 


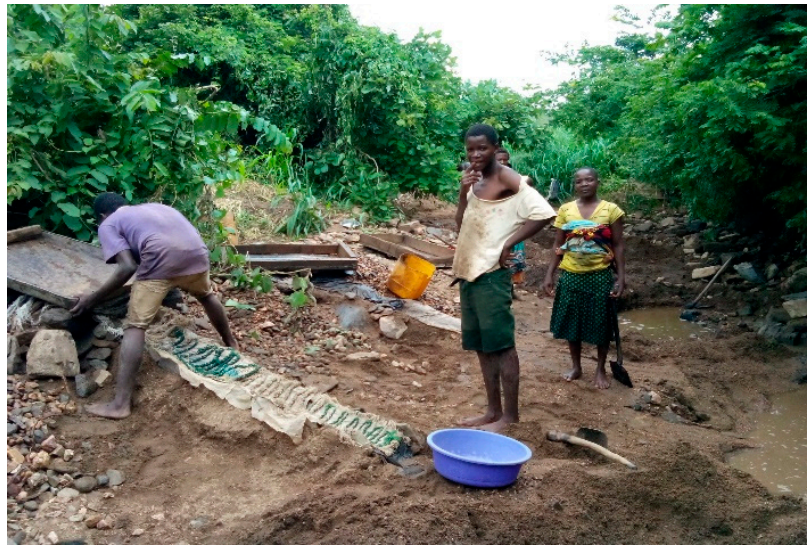

(a)

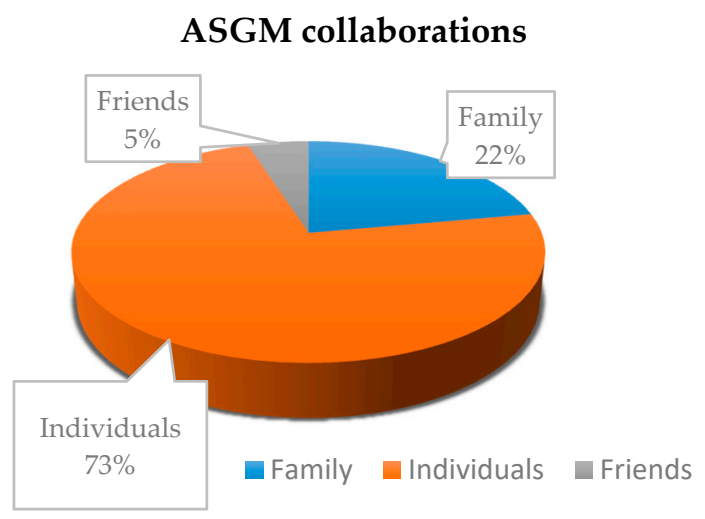

(b)

Figure 3. (a) Separation of alluvial gold from the waste material by the traditional gold panning procedure. (b) Findings of the collaborations during artisanal and small-scale gold mining (ASGM) activities.

Furthermore, the study of the ASGM at various mine sites can reveal that ASGM is characterized by the following:

- Extraction of the alluvial gold ore situated at or near the surface

- The sites are located in remote and isolated locations, in mostly underdeveloped and far off townships

- Miners with low levels of education, mostly at primary school and lacks basic knowledge on mining and geology

- Use of traditional methods and low technological awareness

- Shortage of capital leading to high dependence on manual labour and hand tools

- Minimal levels of environmental, health and safety awareness

It was noted that there are vendors or middlemen who come to the mining hot spots and fund the miners to extract saprolite and alluvial soils from the river basins and riverbanks, and have it processed to win gold using panning procedures. These miners are mostly the indigenous people of the surrounding villages. The final product, very fine gold flakes, is sold to these middlemen. Once a considerable amount has been realized, the vendors or middlemen are invited to buy the products. These middlemen include mostly Malawians and foreign nationals from Tanzania and Mozambique. It was also observed that the miners undertake their activities without an understanding of the legal requirements and provisions for the same. While some miners demonstrated complete ignorance of the provisions of the law, others were aware of the presence of laws and complained about the lengthy process associated with acquisition of mineral rights.

\subsection{Socio-Economic Benefits of ASGM in Malawi}

ASM has provided millions of people a source of income in developing countries within the SADC region [2]. Although farming is the main source of income for the respondents, it was noted that most of the people turn to mining during the dry season, during which farming becomes unfavorable. Therefore, it is evident that ASGM has helped to assuage poverty in places and circumstances where other industries could not.

\subsubsection{Rural Employment}

Rural communities have a minimum of infrastructure and offer an environment where other industries may have serious challenges to operate. ASM offers the local communities a source of informal employment. The study shows that individuals are employed to excavate the waste rock (overburden material), while others are paid for performing the gold panning procedure. It was noted that most of the participants depend on incomes generated directly, and indirectly by the mining activities. These findings auger well with 
results of studies undertaken by $[1,26,27]$ on rural employment emanating from small-scale mining. Particular to this study, it has been determined that the income per fortnight ranges from 2 USD to 223 USD, and the average income per fortnight is about 30.4 USD (Table S1). On the other hand, the income per fortnight from other occupations ranges from 0.25 USD to 108 USD, whereas the average income is approximately 10.72 USD (Table S2). Figure 4 summarizes the comparative earnings from the occupations.

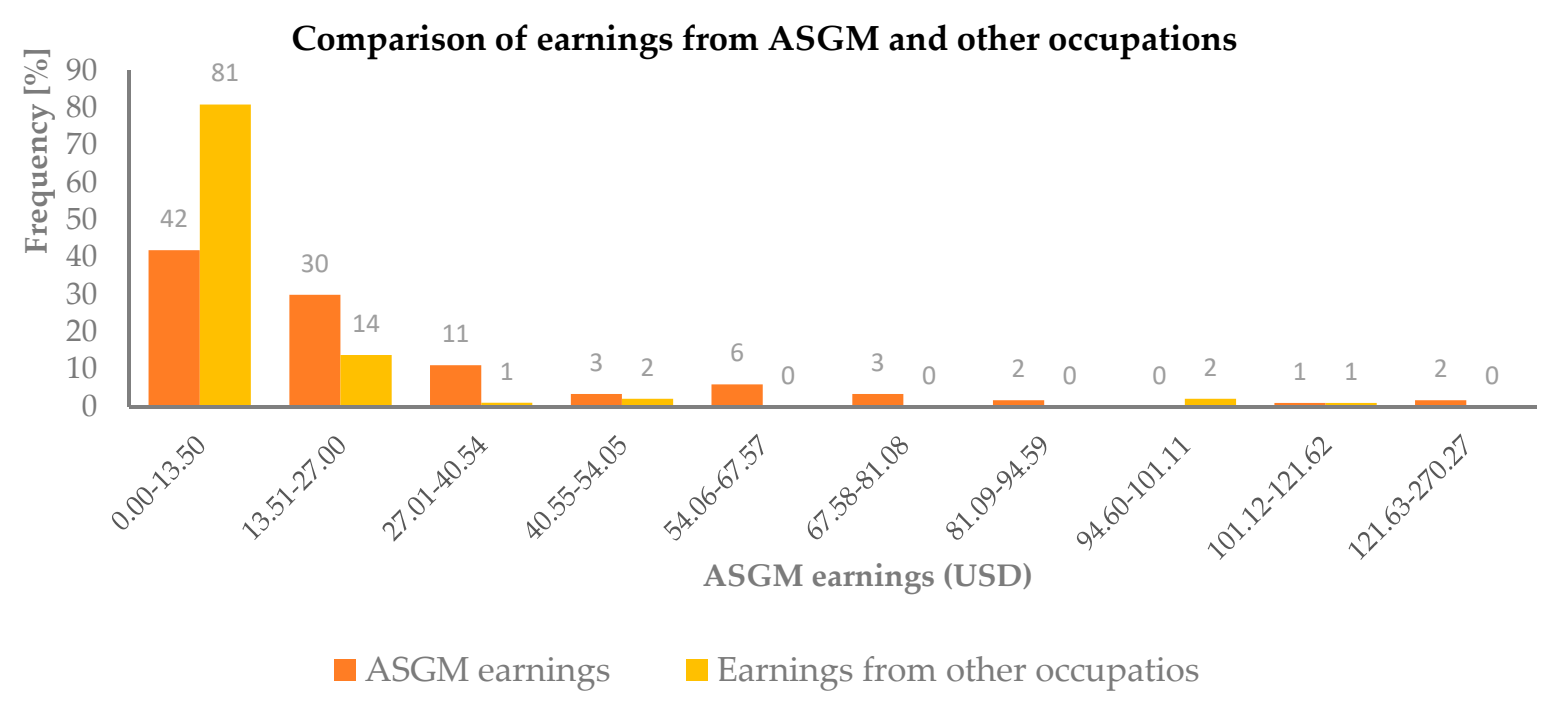

Figure 4. A comparative illustrations of earnings from ASGM activities and other occupations in the visited sites.

A Wilcoxon Signed Rank Test was carried out to compare income from occupation and income from mining instead of the dependent $t$-test, because the data was not normally distributed.

The Wilcoxon Signed Rank Test showed that there was a statistically significant difference in income from other occupations (e.g., farming) and from mining ( $Z=-3.894$, $p=0.000$ ), with $45 \%$ of respondents having mining income more than income from farming and other occupations on the visited sites. There was a 20.97 USD difference in the median for other occupations and mining income.

\subsubsection{Improvement of Livelihood for the Local Communities}

The study notes that the ASGM activities in the visited sites is seasonal; during the rainy season, the local communities are occupied with farming activities. Throughout this time, land for mining is scarce because subsistence farming is prioritized. After the harvesting season is over, the local communities venture into mining as a way of alternative means of income generation to support their livelihoods. The money generated from the mining activities is directly used to support their living. Figure 5 shows how the miners use the mining income to address their needs.

The miners were earning an average of 31 USD per fortnight during the gold rush, however, this is not enough to support their relatively large and extended families. Figure 5 shows that $34 \%$ of the respondents indicated that they use the mining income to buy food, followed by $30 \%$ who indicated clothing as another major use of the money. Immigrants into these mining spots use some of the revenue to pay rents (1\%). In view of the foregoing, it is apparent that the ASGM activities support their very basic needs. Additionally, it is also clear that the main reason for their involvement in ASGM activities is poverty. 


\section{Use of earnings from mining}

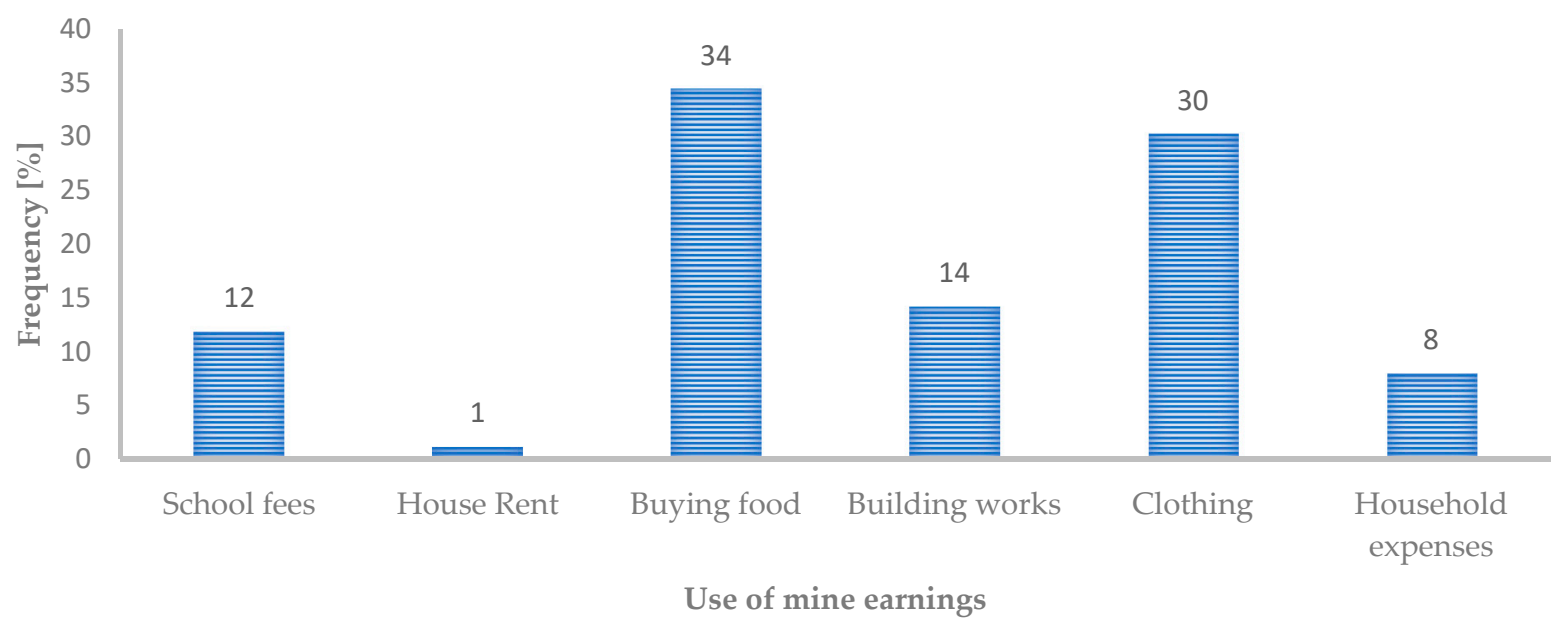

Figure 5. Use of earnings from ASGM activities in the study sites.

\subsection{Marketing Arrangements}

The minerals mined in Malawi have different forms of marketing arrangements depending on their nature. For commercialized commodities such as coal, it is mostly sold locally to the manufacturing industry as a source of energy. In this case, mining companies form agreements with the manufacturing companies on the grade and quantity of coal which is required per certain period of time. For gemstone miners who have licenses, they identify the buyers on their own and the products are sold directly with the Government's permission by issuing export permits. Narrations of the participants, coupled with the results (Figure 6a,b), reveal that there is a need to establish and or improve the existing marketing arrangements for the miners in ASGM. Respondents reported that the extracted gold is sold to vendors; some have settled in the local communities and others visit the sites at designated dates. The gold is sold at low and imposed prices, with the miners lacking bargaining power. None of the respondents indicated that tax is paid during these transactions. This malpractice impedes collection of revenue from this sector. As captured in the data (Figure 6a), 39\% of the respondents reported that buyers for gold are "vendors" who flock into the mining sites to buy the gold, and fellow villagers (39\%) who sell it. Foreigners $(2 \%)$ directly buy the gold at the sites. Furthermore, $13 \%$ reported that they are just employed on the sites for excavation and gold panning, and lacked an understanding on the marketing arrangements.

The middlemen or buyers present serious challenges as the miners sell their gold. Many of the respondents, represented by $36 \%$, reported that the buyers use dishonest scales so that the weight of the gold is lower than the actual weight (Figure 6b). Furthermore, 31\% of the respondents alleged that the miners sell the gold at very low prices, as they do not have an idea on where else they could sell the gold. Interestingly, (Figure 6b) also shows that $18 \%$ of the respondents do not face any challenges during the trade. 


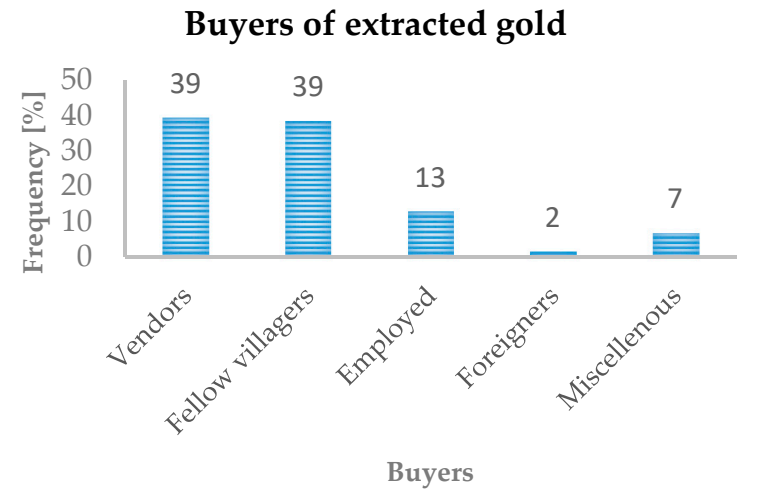

(a)

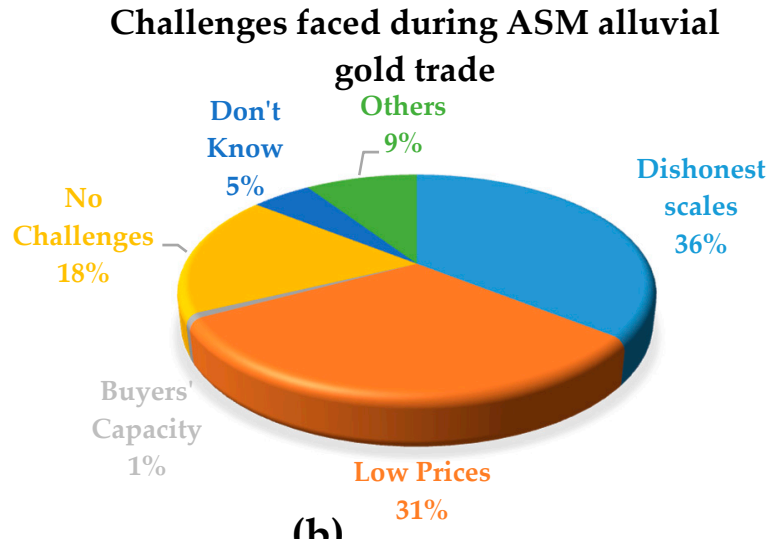

(b)

Figure 6. (a) Presents groups of people who benefit from the ASGM activities such as trading and employment. (b) Captures challenges the miners face during the alluvial gold trade.

\subsection{Challenges and Way Forward}

Considering the low levels of education in these remote areas, and their limited access to geological information, one wonders how the local communities would pin-point gold hot-spots. A study by Zvarivadza [6] in Zimbabwe indicated that some political figures use powers vested in their positions to sustain illegal ASM so that they can access the minerals by buying them at very low prices. It is apparent that there is a lack of political will and negative interference in the development of ASM sector in the SADC region.

On the other hand, the miners have very minimal consideration of the environmental impacts, health, and safety issues associated with unregulated ASGM. Mining activities create pits which are not backfilled and pollute water sources during the gold panning process. All respondents reported that miners do not use safety protective gear during the mining and processing processes.

This study recommends a bottom-up approach intervention in bringing order and sanity in the ASGM sector. This is against the approach of imposing laws and regulations without engaging ASGM miners as some of the key stakeholders in developing the laws and regulations which affect them. Suggestions from the local communities in the mining hot-spots were solicited and have been presented in Figure 7.

As illustrated in Figure 7,3\% of the respondents suggested the need for loans from government to support their activities, while $37 \%$ indicated the need for capital to enable them procure mining related equipment such as water pumps, jack hammers, and related pieces of equipment. Others $(16 \%)$ recommended that government should establish proper marketing channels for the ASGM activities. Establishing proper and effective marketing arrangements in ASGM sector can offer a fair-trade situation which subsequently protects the miners against middlemen and or buyers who take advantage of their market ignorance and rob them of their hard-mined gold. In addition, this may also help government widen its resource through revenue collection in form of taxes.

Furthermore, 5\% of the respondents (Figure 7) noted that there is a need to create geological reserve areas for potential investors and or government to undertake detailed geological explorations and market these sites to investors who can develop the resources. This can lead to the opening of mines in such communities, thereby providing a formal source of employment. Other respondents (17\%), as shown in the same Figure, noted that the process of acquisition of mineral rights is lengthy. Various fees being demanded from a poor ASGM miner, the rigidity of the process for issuing the license, and lengthy time delays when processing a mining license discourage potential small-scale mining investors from operating within the legal perimeters. There is need to create mining desk officers in the district councils where there are mining related activities so that they address some of these challenges. The practices of ASM in the local communities need to be studied 
and eventually absorbed into the legislation. It was noted that most of the indigenous communities are highly ignorant about Malawi's mining laws; therefore, there is a need to raise awareness of the legal requirements provided for the sector. The use of force in stopping illegal small-scale mining has proven futile as it promotes abjection and deprives miners of a source of income for their survival. Based on the recent approaches in Malawi for curbing illegal small-scale mining, it can be concluded that use of state security forces to stop and scare gold-miners from accessing gold hot spots has not solved the problem, but rather promoted community suffering and poverty.

\section{Recommendations from the study participants}

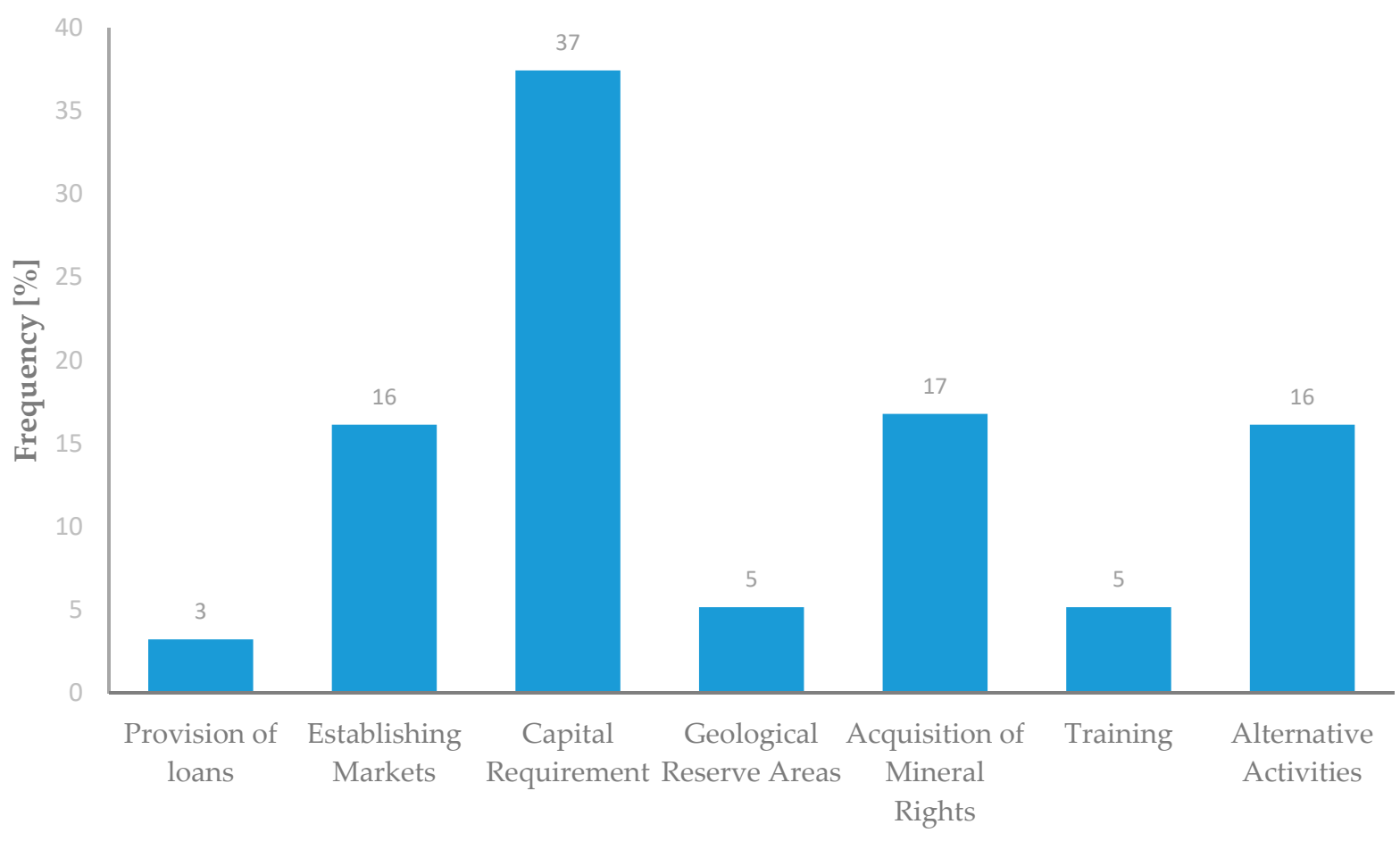

Respondents' suggestions

Figure 7. Suggestions from the local communities on proposed interventions from government, private sector, and other stakeholders for promoting the ASGM in Malawi.

\subsection{Significance of the Study}

There have been very few studies in Malawi addressing the socioeconomic aspect of the extractive sector, particularly those of ASM activities. This study is very important because it offers a starting point for capturing primary information regarding the role of ASGM in alleviating poverty in Malawi's rural communities. This study has revealed that there are relatively higher incomes from ASGM activities as compared to other occupations. It suggests that, in these rural areas, the wages which the ASGM workers get are higher than those received from other occupations such as farming (Figure 4). It further exposes the irresponsibility of the miners with regards to protection of the environment, and the minimal safety considerations. This study exposes the fight against absolute poverty in the rural and marginalized communities. As alluded to elsewhere in this work, the primary reason for engagement in ASGM activities in these rural communities is poverty-they use their ASGM income to meet their very basic needs such as food and clothing. This might explain the observation that ASGM in Malawi is dominated by women who traditionally take a leading role in fetching the basic needs of the homes.

The study notes that ASGM is also triggered by middlemen who take advantage of the abject poverty in these remote and marginalized rural communities. This is exacerbated 
by poor enforcement of mineral laws for the artisanal and small-scale mining subsector. A relatively small proportion of the local communities is aware of the basic legal requirements (need to acquire mineral rights) but possibly ignore them due to the cumbersomeness of the process.

It has been observed that the emphasis of the Government and civil society organizations is on the legal compliance of the ASGM operations without providing alternative solutions to keep the miners at work. This study recommends provision of mining related extension services, including monitoring and inspection to the rural communities. Additionally, marketing centers should be introduced where prices of gold and other precious minerals are properly regulated by a government agency. This recommendation has the potential to form a starting point towards formalization of the ASGM sub-sector.

The current research offers unique insights of the socioeconomic benefits of ASGM because it has uncovered the end usage of the revenues generated from the activities. It has been established that the earnings realized from mining, though not enough, are used for livelihood sustenance. This is different from other studies which have emphasized employment rate in the sector without necessarily unearthing the actual earnings. Clearly, employment rate can be a misleading metric if the attendant earnings figures are not reported, as is the case in most publications herein cited.

Finally, it has also been revealed that ASGM activities in Malawi slightly depart from the practices in other African countries, particularly in the use of mercury. For example, despite several visits in the sites, there was no evidence pointing to the use of mercury during the gold separation process. This appears to be different from other ASGM practicing countries such as Zimbabwe, Ghana, Burkina Faso, and other developing countries where there is an extensive use of mercury during the amalgamation process $[4,10,28-30]$.

\section{Conclusions}

There is an urgent need to ensure that the ASGM sector is formalized so that it significantly contributes to the overall development of the country. ASGM has the potential to make significant contribution to the revenue generation of the Malawi Government, providing employment to the local communities, and initiating other forms of economic activities in these remote and undeveloped areas. A bottom-up approach is recommended to develop effective regulations which support the sector. This study has noted that poverty is one of the major reasons why most ASGM miners are involved with illegal small-scale gold mining activities in Malawi. ASGM operations, which involve hard labor, are one of the few options the local communities can pursue to support their livelihood. The study shows that income generated by the mining activities is used mainly to help them meet their very basic needs such as food and clothing. If the sector is fully supported, it is most likely to assist in poverty alleviation in Malawi's remote areas which have gold occurrences. Whereas this study notes that poverty is the major trigger factor for the increase in ASGM activities in Malawi, there is need for further research to identify and validate other factors which promotes unregulated ASGM activities in Malawi and other developing countries.

Supplementary Materials: The following are available online at https:/ / www.mdpi.com/2673-648 9/1/1/3/s1, Table S1: income from ASGM activities per fortnight, Table S2: income per fortnight from other occupations (including farming).

Author Contributions: Conceptualization, T.H., S.G. and T.M., Data curation, T.H., A.K.; Formal Analysis, A.K., T.H.; Funding acquisition, T.H., T.M.; Investigation, T.H., A.K., G.T., T.M., S.G.; Methodology, T.H., T.M., A.K.; Project Administration, T.H.; supervision, T.H., T.M.; Validation, T.H., G.T., S.G.; Visualisation, T.H., S.G., G.T.; Writing-Original draft, T.H. All authors have read and agreed to the published version of the manuscript.

Funding: This research was funded by the Polytechnic, a constituent college of the University of Malawi through the Mining Engineering Department budgetary allocation on Research and Publications.

Institutional Review Board Statement: Not applicable. 
Informed Consent Statement: Not applicable.

Data Availability Statement: Not applicable.

Acknowledgments: The authors express deep gratitude and appreciation to University of Malawi, the Polytechnic for the financial support it has provided towards execution of the study.

Conflicts of Interest: The authors declare no conflict of interest. This is the original work of the authors, and the manuscript has not been submitted elsewhere for publication. Furthermore, the funders had no role in the design of the study; in the collection, analyses, or interpretation of data; in the writing of the manuscript, or in the decision to publish results.

\section{References}

1. Hilson, G. Small-scale mining, poverty and economic development in sub-Saharan Africa: An overview. Resour. Policy 2009, 34, 1-5. [CrossRef]

2. Drechsler, B. Small-scale mining and sustainable development within the SADC region. Min. Miner. Sustain. Dev. 2001, 84, 165. Available online: http:/ / commdev.org/files/1798_file_asm_southern_africa.pdf (accessed on 10 July 2020).

3. Hilson, G. Small-scale mining in Africa: Tackling pressing environmental problems with improved strategy. J. Environ. Dev. 2002, 11, 149-174. [CrossRef]

4. Maponga, O.; Ngorima, C.F. Overcoming environmental problems in the gold panning sector through legislation and education: The Zimbabwean experience. J. Clean. Prod. 2003, 11, 147-157. [CrossRef]

5. Siegel, S.; Veiga, M.M. Artisanal and small-scale mining as an extralegal economy: De Soto and the redefinition of 'formalization'. Resour. Policy 2009, 34, 51-56. [CrossRef]

6. Zvarivadza, T. Artisanal and Small-Scale Mining as a challenge and possible contributor to Sustainable Development. Resour. Policy 2018, 56, 49-58. [CrossRef]

7. EITI Malawi. "Malawi Industries Transparency Initiative Report" BDO LLP. 2019, p. 61. Available online: http://www.jsd-africa. com/Jsda/Fall2006/PDF/Arc_theExtractiveIndustriesTransparencyInitiative.pdf (accessed on 22 December 2020).

8. Government of Malawi. Malawi Growth Development Strategy; Government Printer: Lilongwe, Malawi, 2005 ; pp. 33-34.

9. $\quad$ Ezekwesili, O.K.; Baxter, M.; Gilbo, T.; Sa, D.P.; Land, B.; Husband, C. Malawi: Mineral Sector Review, Source of Economic Growth and Development; World Bank: Colombia, WA, USA, 2009.

10. UNEP. Reducing Mercury Use in Artisanal and Small-Scale. United Nations Environ. Policy. 2012, p. 76. Available online: http:/ / www.unep.org/hazardoussubstances/Portals/9/Mercury/Documents/ASGM/Techdoc/UNEPTechDocAPRIL2 012_120608b_web.pdf (accessed on 28 October 2020).

11. World Health Organization. Artisanal and Small-Scale Gold Mining and Health-Technical Paper \#1: Environmental and Occupational Health Hazards Associated with Artisanal and Small-Scale Gold Mining; WHO Document Production Services; WHO: Geneva, Switzerland, 2016; p. 26.

12. Grynberg, R.; Kandaswamy, V.; Singogo, F. The ASGM sector in Africa-A child of misery and desperation? Dev. South. Afr. 2021. [CrossRef]

13. Mwakumanya, M.A.; Maghenda, M.; Juma, H. Socio-economic and environmental impact of mining on women in Kasigau mining zone in Taita Taveta County. J. Sustain. Min. 2016, 15, 197-204. [CrossRef]

14. Amegbey, N.A.; Dankwa, J.B.K.; Al-Hassan, S. Small scale mining in Ghana-Techniques and environmental considerations. Int. J. Surf. Min. Reclam. Environ. 1997, 11, 135-138. [CrossRef]

15. Carter, G.S.; Bennett, J.D. Geology and mineral resources of Malawi. Malawi Geol. Surv. Dep. Bull. 1973, 6, 1-62.

16. King, A.W.; Dawson, A.L.; Malawi. Geological Survey Department. The Geology of the Mangochi-Makanjila Area; Government Printer: Zomba, Malawi, 1976.

17. Walter, M. The Geology of the Lilongwe-Dowa Area; Government Printer: Zomba, Malawi, 1972.

18. Thatcher, E.C.; Walter, M.J. The Geology of the South Lilongwe Plain and Dzalanyama Range; Government Printer: Zomba, Malawi, 1968.

19. Bloomfield, K.; Garson, M.S.; Ashley, B.E. The Geology of the Kirk Range, Lisungwe Valley Area; Government Printer: Zomba, Malawi, 1965.

20. Chisambi, J.; von der Heyden, B.V.; Tshibalanganda, M.; le Roux, S. Gold exploration in two and three dimensions: Improved and correlative insights from microscopy and X-ray computed tomography. Minerals 2020, 10, 476. [CrossRef]

21. Marshall, B.G.; Veiga, M.M. Formalization of artisanal miners: Stop the train, we need to get off! Extr. Ind. Soc. 2017, 4, 300-303. [CrossRef]

22. Mines and Minerals Act 2019. (C.61:01). Available online: https://malawilii.org/mw/consolidated_legislation/6101 (accessed on 16 June 2020).

23. Taherdoost, H. Sampling Methods in Research Methodology; How to Choose a Sampling Technique for Research. SSRN Electron. J. 2016. [CrossRef]

24. Taherdoost, H. Determining sample size; How to calculate survey sample size. Int. J. Econ. Manag. Syst. 2017, 2, 237-239. Available online: http:/ / www.iaras.org/iaras/journals/ijems (accessed on 14 July 2020). 
25. Barlett, J.E.; Kotrlik, J.; Higgins, C. Organizational Research: Determining Appropriate Sample Size in Survey Research. Inf. Technol. Learn. Perform. J. 2001, 19, 43.

26. Hilson, G. Small-scale mining and its socio-economic impact in developing countries. Nat. Resour. Forum 2002, 26, 3-13. [CrossRef]

27. Hinton, J.J.; Veiga, M.M.; Veiga, A.T.C. Clean artisanal gold mining: A utopian approach? J. Clean. Prod. 2003, 11, 99-115. [CrossRef]

28. Hilson, G. A contextual review of the Ghanaian small-scale mining industry. Min. Miner. Sustain. Dev. 2001, 76, 29. Available online: http:/ / pubs.iied.org/pdfs/G00722.pdf (accessed on 18 July 2019).

29. Lombe, W.C. Small Scale Mining and the Environment: Bloom beyond the doom and gloom? J. Clean. Prod. 2003, 11, 95-96. [CrossRef]

30. Grätz, T. Moralities, risk and rules in West African artisanal gold mining communities: A case study of Northern Benin. Resour. Policy 2009, 34, 12-17. [CrossRef] 